\title{
Application of the Morphological Analysis for the Synthesis Arrangements of Industrial Robots with Parallel Structure Mechanisms
}

\author{
Ibrahim Farhan Salman Alrefo \\ College of Ma'an, Al-Balqa' Applied University, Salt, Jordan \\ Email: ibrahemrf73@yahoo.com
}

Received 1 February 2016; accepted 1 May 2016; published 5 May 2016

Copyright (C) 2016 by author and Scientific Research Publishing Inc.

This work is licensed under the Creative Commons Attribution International License (CC BY).

http://creativecommons.org/licenses/by/4.0/

(c) (i) Open Access

\begin{abstract}
The main features of morphological model of industrial robots are discussed, such as support system, manipulator and gripping device. These features are presented with the alternatives for their realization as separate modules. The examples of synthesis of arrangements of industrial robots are resulted on module principle with writing of their morphological formulas.
\end{abstract}

\section{Keywords}

Morphological Analysis, Industrial Robot, Arrangement, Module Principle, Mechanism of Parallel Structure

\section{Introduction}

When creating a new generation of technological equipment, special attention must be devoted to the Mechanisms of Parallel Structure (MPS) [1]. They began to be used not only in machine tools, but also in other vehicles, especially in industrial robots [2]. This is due to the following advantages: high rigidity, low metal consumption, low inertia mass movable rod assemblies, high acceleration movement of the executive body, and increase of the member of degrees of mobility of object manipulation.

It is the latter advantages MPS influenced the development of industrial robots, which are accepted as associated human-device capable of performing almost all the work which is executed man [3]-[5].

A variety of design of industrial robots and related control systems are divided into three generations [4]. The first is a simple design and relatively low cost of a hard cycle control; the second-complex design and more advanced memory in the form of computers and information system, industrial robot enables singles to get some 
information about the environment (by means of position sensors, force, view etc.); the third is on the design and improvement of information and control devices, approaching the man.

When intelligent industrial robots are in development, rapid deployment into production is expected in the coming years, as their design requires finding new layout solutions.

The creation of industrial robots of the third generation is common efforts of many scientists and experts from many countries [1] [2] [4]-[9], among which: USA (University of Florida, Johns Hopkins University, Catholic University of America, Northwestern University); Canada (University Laval, McGill University, University of Toronto); Japan (University of Tokio, Osaka University, Tohoko University); South Korea (Seoul National University, KAIST); Israil (Technion-Israi Institute of Technology); Germany (Technical Universities Hamburg - Harburg, Braunschweig IFH, University Hannover-IFW); Switzerland (EPFL); Great Britain (Leicester University); Belgia (Katholieke University Leuven); China, Russia, Ukraine and other countries. Detailed information in this area is collected at the Department of Designing Tools and Machines in National Technical University of Ukraine "Kyiv Polytechnic Institute" and presented in the monograch [1].

When searching for new layouts of industrial robots, effective systematic-morphological approach is widely used in creative activities [10] and as a new scientific approach, it is related to the evolutionary synthesis and genetic synthesis of the technical systems [11] [12].

\section{Problems}

The purpose of research-morphological analysis and synthesis option schemes arrangements of industrial robots with MPS and the modular design principle for the future choose the best option based on specified criteria.

\section{Solving the Problems}

As is known the method of morphological analysis involves five sequential steps [10]:

1) Statement of the problem (clarification of tasks, reflecting the basic requirement of the object-industrial robot with MPS).

2) Decomposition of the object (a division of industrial robot for the main morphological characters, principally depends on the software-defined requirements).

3) Composition of the morphological model (a set of options (alternatives) for each morphological character) -building morphological table and matrices.

4) Synthesis of the variants of the object (the analysis of functional values in the form of morphological formulas).

5) Selection of the best solutions (selection of several, usually two or three, the best rational, sometimes optimal, solutions based on a specified criterion).

6) Considering task of arrangements on step 1 with updating it's, proceed to step 2-decomposition (Figure 1).

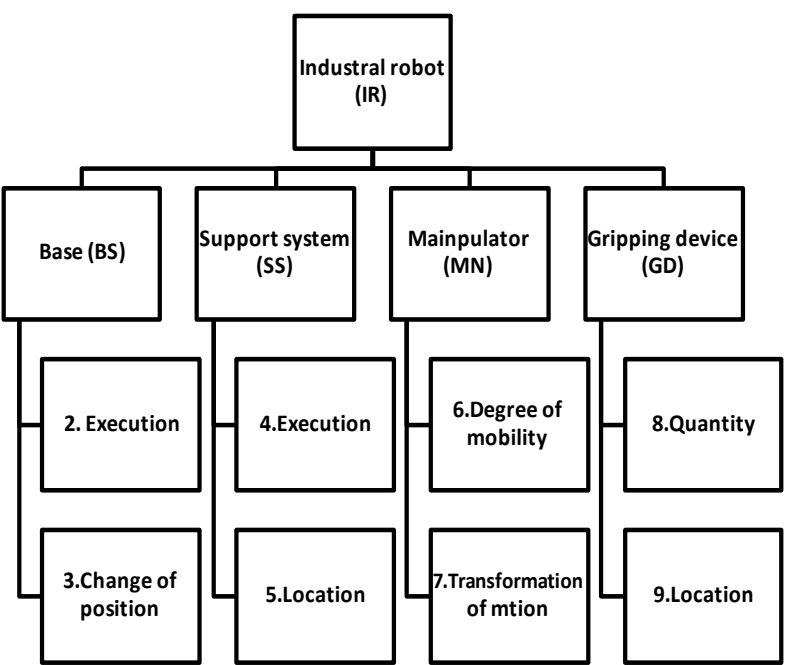

Figure 1. Main features of the morphological model of industrial robot. 
For each of eight characters (signs) on step 3 choose alternatives and form a morphological model in the form of a morphological Table 1, which is proposed by the author for the first time.

Morphological matrix in a minimized form

$$
M_{A R}=M_{B S} \wedge M_{S S} \wedge M_{M N} \wedge M_{G D},
$$

where $M_{B S}, M_{S S}, M_{M N}, M_{G D}$-morphological matrixes respectively base, support system, manipulator, gripping device.

Morphological matrix in expanded form

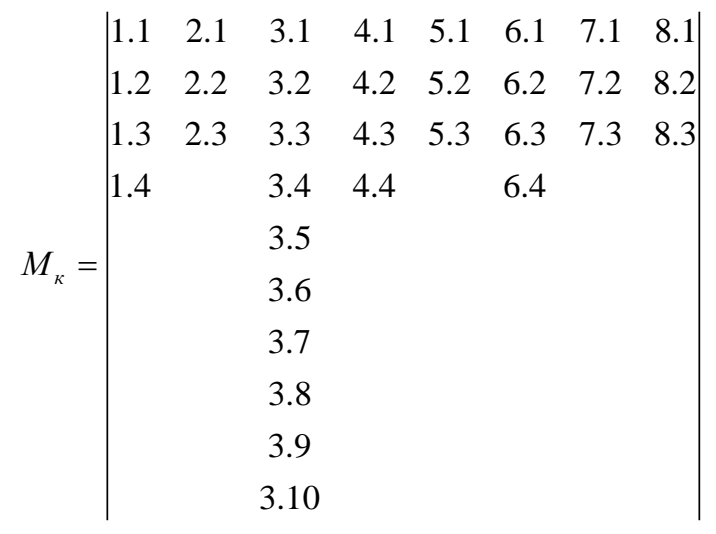

The total number of solutions $N_{A R}=4 \times 3 \times 10 \times 4 \times 3 \times 4 \times 3 \times 3=51840$. Among them there are unusual versions of the original that could be missed with a simple search and does not in sight.

Examples of implementation of morphological matrix performance base (feature 1) and performance support system (feature 3) are shown in Figure 2 and Figure 3.

For the implementation of new arrangements of industrial robots with MPS, a modular principle can be used [1] [6] [13] with a set of unified assemblies and modules. These facilities reduce the complexity and time of manufacturing. This facilities specialized industry reduces the complexity and time of manufacture.

Furthermore this principle allows a qualified designer using the problem-oriented CAD/CAE system to develop a scheme of General layout of industrial robot to ensure that his assistants could be based on a standard software for automated design, typical of calculations and information from databases, design of industrial robot, picking ready purchase components and parts over the Internet to supply the factory Assembly type.

Enables the implementation of concurrent product development (concurrent engineering), that is simultaneous execution in a short time project works and preparation of production for the purpose of synchronization.

The minimum set of modules and the nominal image are presented in Table 2. With their help it is convenient to depict the layout and the stage of search design [1] [4].

\begin{tabular}{|c|c|c|c|c|c|c|c|}
\hline \multicolumn{2}{|l|}{ Base (BS) } & \multicolumn{2}{|l|}{ Support system (SS) } & \multicolumn{2}{|c|}{ Manipulator (MN) } & \multicolumn{2}{|c|}{ Gripping device (GD) } \\
\hline 1. Execution & $\begin{array}{l}\text { 2. Change of } \\
\text { position }\end{array}$ & 3. Execution & 4. Location & $\begin{array}{l}\text { 5. Degree } \\
\text { of mobility }\end{array}$ & $\begin{array}{l}\text { 6. Transformation of } \\
\text { motion }\end{array}$ & 7. Quantity & 8. Location \\
\hline $\begin{array}{l}\text { 1.1. Outdoor } \\
\text { 1.2. Ceiling } \\
\text { 1.3. Wall } \\
\text { 1.4. } \\
\text { Combined }\end{array}$ & $\begin{array}{l}\text { 2.1. Absent (fixed) } \\
\text { 2.2. Mobile for } \\
\text { one coordinate } \\
\text { 2.3. Mobile for } \\
\text { two coordinate }\end{array}$ & 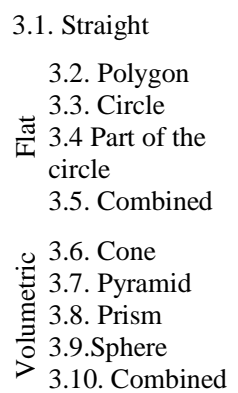 & $\begin{array}{l}\text { 4.1. Upright } \\
\text { 4.2. Horizontal } \\
\text { 4.3. Oblique } \\
\text { 4.4. Combined }\end{array}$ & $\begin{array}{l}\text { 5.1. One } \\
\text { 5.2. Two } \\
\text { 5.3. Several }\end{array}$ & $\begin{array}{l}\text { 6.1. Chaining the length } \\
\text { of rod (-pod) } \\
6.2 \text {. Chaining the } \\
\text { position } \\
\text { the support rod (-glayd) } \\
6.3 \text {. Chaining the angle } \\
\text { of rotation of rod (delta) } \\
6.4 \text {. Combined }\end{array}$ & $\begin{array}{l}\text { 7.1. One } \\
\text { 7.2. Two } \\
\text { 7.3. Several }\end{array}$ & $\begin{array}{l}\text { 8.1. Perpendicular to } \\
\text { the plane of the } \\
\text { mobile platform } \\
\text { 8.2. Along (parallel } \\
\text { to) he plane of the } \\
\text { mobile platform } \\
\text { 8.3. At any angle }\end{array}$ \\
\hline
\end{tabular}

Table 1. The morphological model of arrangements of industrial robots with mechanisms of parallel structure. 
a)

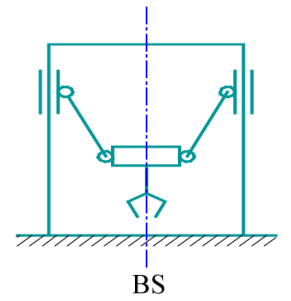

b)

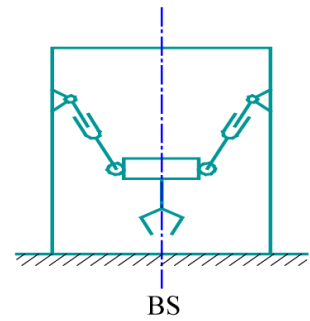

1.2

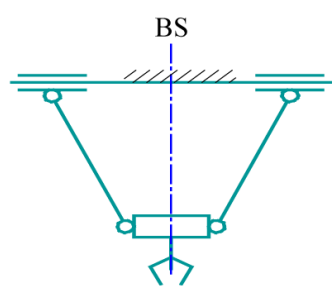

1.2

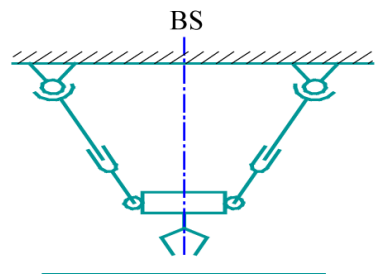

BS
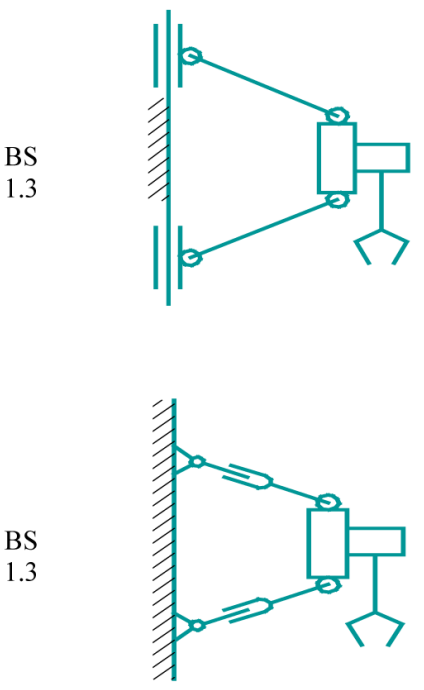

BS

Figure 2. Examples of execution base of the industrial robot as type: a-biglayd; b-bipod.

3.1

1
3.2

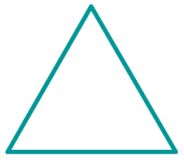

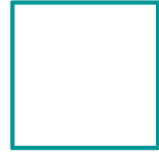

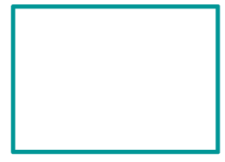

3.3

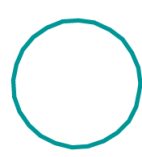

3.4
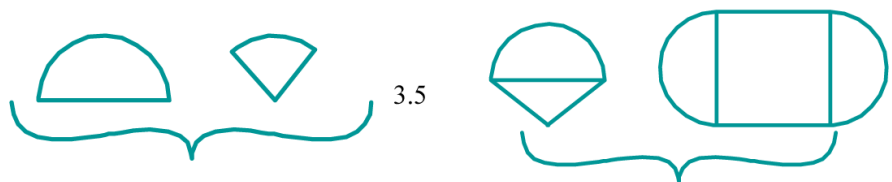

3.8

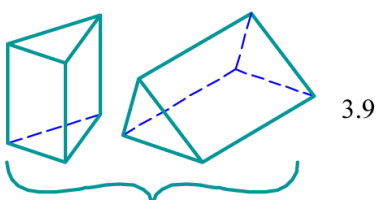<smiles>C1CC2CCC(C1)C2</smiles>

3.9

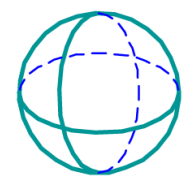

Figure 3. Examples of performance support system of the industrial robot.

\section{Examples}

As example the implementation step 4 (Figure 4) of the possible schemes of arrangement of industrial robots with MPS, described by the following morphological formulas:

$$
\begin{aligned}
& X_{1}=|1.2-2.2|-|3.1-4.2|-|5.3-6.2|-|7.2-8.3| \\
& X_{2}=|1.1-2.1|-|3.7-4.1|-|5.3-6.2|-|7.1-8.1| \\
& X_{3}=|1.4-2.1|-|3.8-4.1|-|5.3-6.1|-|7.2-8.1|
\end{aligned}
$$

The choice of the best variants of the scheme of arrangement of industrial robots with MPS on step 5 for a 
Table 2. The minimum set of modules for arrangement of industrial robots with mechanisms of parallel structure.

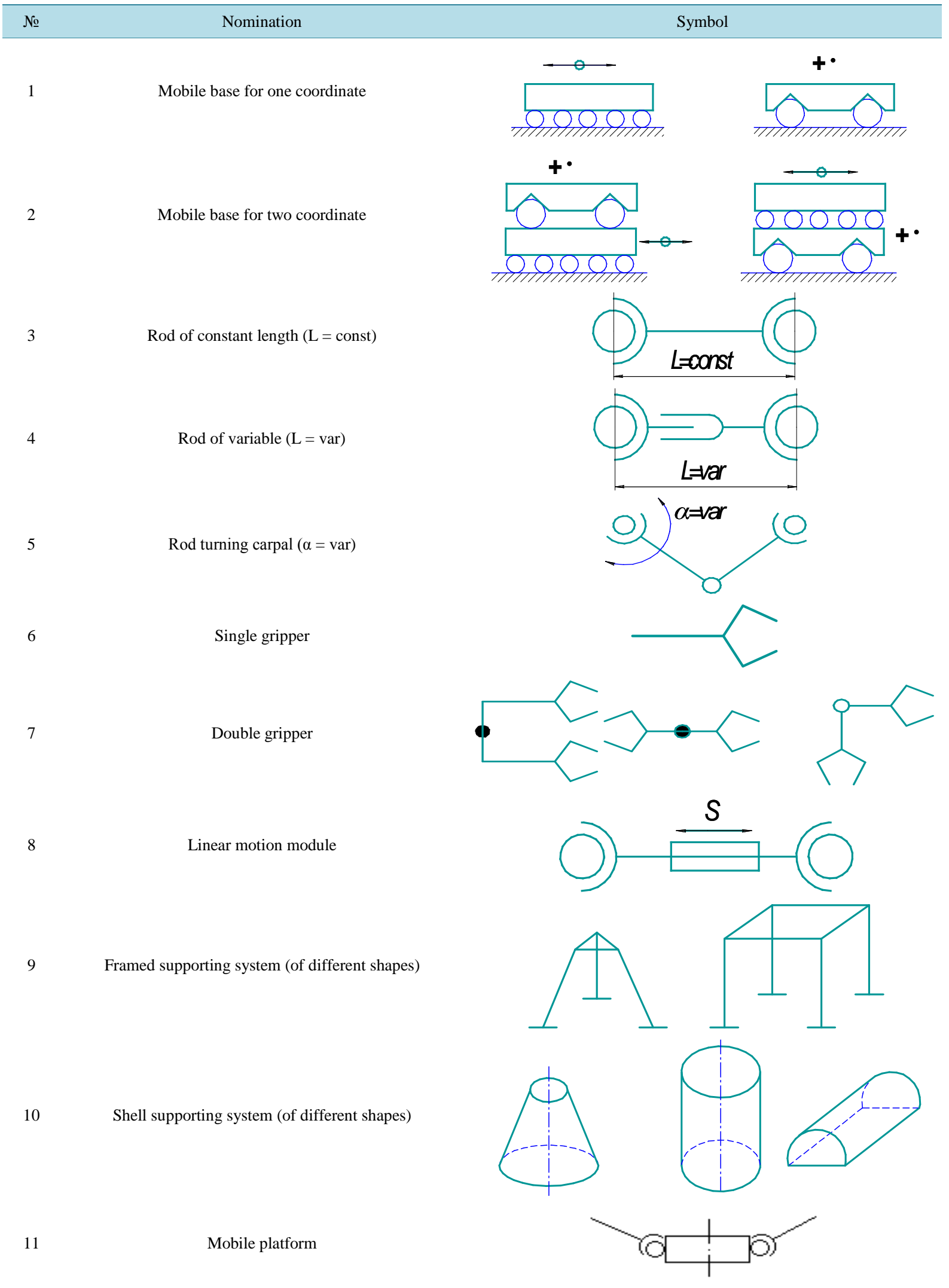


(a) 1.2

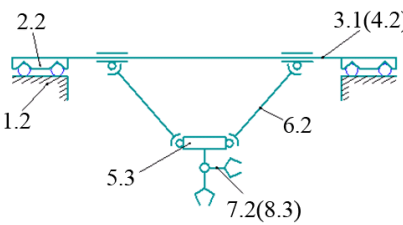

(b)
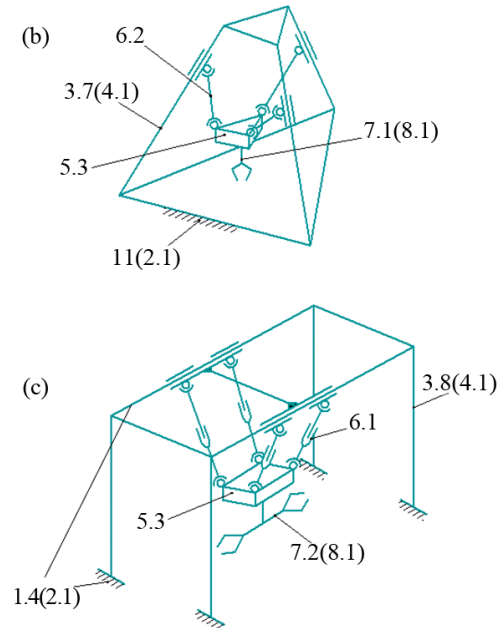

Figure 4. Synthesized arrangements of industrial robots with mechanisms of industrial robots with mechanisms of parallel structure, appropriates morphological formulas: (a) $x_{1}$ (3); (b) $x_{2}(4)$; (c) $x_{3}$ (5).

given criterion, for example, the stiffness of support system, is performed using one of the methods of expert estimates [10].

\section{Conclusion}

The proposed system-morphological approach and morphological model with the basic morphological features (base, support system, manipulator, gripping device) allow construction at the stage of sea to consider a variety of options schemes of industrial robots with mechanisms of parallel structure, followed by selection of the best options for further development of the constructs.

\section{References}

[1] Kuznetsov, Y.N., Dmitriev, D.A. and Dinevich, G.E. (2010) Layout Machines with Mechanisms of Parallel Structure. Vishemirsky V.S., Kherson, 471 p.

[2] Merlet, J.P. (2006) Parallel Robot. Springer, Dordrecht, 417 p.

[3] Alrefo, I.F.S., Hamuyela, Zh.A.H. and Kuznetsov, Y.N. (2015) Genetic and Morphological Approach for Description and Synthesis of Gripping Devices of Robots and Manipulators. Journal of the Technical University of Gabrovo, 49, 8-10.

[4] Pavlenko, I.I. (2007) Industrial Robots: The Basics Calculation and Design. KNTU, Kirovograd, 420 p.

[5] Yaglinsky, V.P. (2008) Kinematics of Robots with Parallel Structure. MOTROL, Motorization and Power Industry in Agriculture, Lublin, Vol. 10A, 105-114.

[6] Yang, G.L., Chen, I.M., Lim, W.K. and Yeo, S.H. (1999) Design and Kinematics Analysis of Modular Reconfigurable Parallel Robots. Proceedings of the 1999 IEEE International Conference of Robotics \& Automation, Detroit, May 1999, 2501-2506.

[7] Kim, H.S. and Tsai, L.-W. (2002) Design Optimization of a Cartesian Parallel Manypulator. Proceedings of DETC-02 ASME 2002, Design Engineering Technical Conference and Computer and Information in Engineering Conference, Montreal,

[8] Liu, G.F., Wu, Y.L., Wu, X.Z., Kuen, Y.Y. and Li, Z.X. (2001) Analyses and Control of Redundant Parallel Manipulators. Proceeding of the 2001 IEEE International Conference of Robotics \& Automation, Vol. 4, 3748-3754. 
[9] Wen-jia C., Ming-yang Z. and Ling, Y. (2002) A Six-Leg Four-DOF Parallel Manipulator. 3rd Chemnitz Parallel Kinematics Seminar, Chemnitz, 227-240.

[10] Kuznetsov, J.N., Hamuyela, J.A. Guerra and Hamuyela, T.O. (2012) Morphological Synthesis Machines and Mechanisms. K.: Ltd “Gnosis” Ltd., 416 p.

[11] Schinkarenko, V. and Kuznetsov, Y. (2011) Genetic Programs of Complex Evolutionary Systems (Part 1, 2). 11th Anniversary International Scientific Conference “UNITECH-11”, 18-19 November, Gabrovo, Vol. 1, 33-52.

[12] Shinkarenko, V.F. (2002) The Basics of Evolution of Elektromechanical Systems. K.: NaukovaDumka, 288 p.

[13] Kuznetsov, Y.N. and Shibetsky, V.Y. (2012) Robotic Systems and Complexes of Pharmacentical and Biotehnology Industries. K.: Ltd “Gnosis”, 335 p. 